\title{
Hubungan Kualitas Air Minum dan Kebiasaan Makan/Minum di Luar Rumah dengan Terjadinya Demam Tifoid pada Pasien Rawat Inap di RSUD Kota Kendari
}

\author{
Zida Maulina Aini \\ Bagian Mikrobiologi, Fakultas Kedokteran, Universitas Halu Oleo, Kendari \\ Corresponding author email : zidamaulina@gmail.com
}

\begin{abstract}
ABSTRAK
Latar Belakang: Demam Tifoid adalah penyakit yang disebabkan oleh infeksi bakteri Salmonella Typhi melalui makanan atau minuman yang terkontaminasi. Tahun 2016, demam tifoid masuk dalam 10 penyakit menular tertinggi di Sulawasi Tenggara yaitu berada pada peringat ke-5 dengan jumlah kasus sebanyak 4.641 penderita. Tujuan dari penelitian ini adalah untuk mengetahui hubungan kualitas air minum, sumber air bersih dan kebiasaan makan/minum di luar rumah dengan terjadinya demam tifoid pada pasien rawat inap di RSUD Kota Kendari. Metode: Jenis penelitian ini adalah deskriptif-observasional dengan rancangan cross sectional. Lokasi penelitian ini berada di RSUD kota Kendari dan Laboratorium Fakultas Kedokteran Universitas Halu Oleo. Populasi kasus dari penelitian ini adalah semua pasien yang dirawat inap dengan demam >3 hari diruang rawat inap RSUD Kota Kendari pada bulan Januari-Februari 2018 yang memenuhi kriteria inklusi dan eksklusi. sejumlah 38 orang. Instrumen penelitian berupa kuesioner. Data dianalisis dengan rumus uji Chi-square. Hasil: Hasil penelitian menunjukan bahwa dari 38 responden, yang memenuhi syarat untuk kualitas air minum adalah sebanyak 16 responden sedangkan yang tidak memenuhi syarat sebanyak 22 responden dengan nilai p sebesar $(p=0,544)$. Sementara itu, ada sebanyak 20 responden dengan kebiasaan makan/minum di luar rumah yang baik dan 18 responden dengan kebiasaan makan/minum diluar rumah yang kurang baik dengan nilai $p$ sebesar $(p=0,049)$. Simpulan: Penelitian ini menyimpulkan bahwa tidak ada hubungan antara kualitas air minum dengan terjadinya demam tifoid, serta ada hubungan kebiasaaan makan/minum diluar rumah dengan terjadinya demam tifoid pada pasien rawat inap di RSUD kota kendari.
\end{abstract}

Kata kunci : demam tifoid, kebiasaan makan/minum luar rumah, kualitas air minum

\begin{abstract}
Background: Typhoid fever is a disease which arouse from the infection from Salmonella Typhi superbug through either the contaminated food or drink. It is recorded in 2016, Typhoid fever belongs to the highest ten contagious diseases in Southeast Sulawesi and comes in fifth with the cases of 4.641 sufferers. Purpose: This research study is aimed to know the bearing of quality of water, source of hygienic water and outdoor eating/drinking habit and the cause of typhoid fever to inpatients at Regional General Hospital in Kendari. Method: This research is an observationaldescriptive study with a cross sectional design. 38 people of all the inpatients who had more than three days fever were used to be the total of sampling of this research. The instrument of this study is in the form of questioner. The Chi-square trial formula at significant rates $(\alpha=0.05)$ was used in this research to analyze the data. Result: It is found that out of the 38 respondents, those who measure up for the quality of water are 16 respondents while who do not are 22 respondents with the value of $(p=0,544)$. Meanwhile, there are 20 respondents of good outdoor eating or drinking habit and 18 respondents of the bad one with the value of $(p=0,049)$.
\end{abstract}

Keyword: typhoid fever, outdoor eating/drinking habit, quality of water 


\section{PENDAHULUAN}

Demam tifoid adalah infeksi sistemik yang di sebabkan oleh kuman Salmonella typhi, $S$. paratyphi $A, S$. paratyphi $B$ dan $S$. paratyphi $C$, biasanya melalui konsumsi makanan atau air yang terkontaminasi (Inawati, 2009). Berdasarkan profil kesehatan Indonesia tahun 2009, demam tifoid dan paratifoid masuk dalam 10 penyakit terbanyak pada pasien rawat inap di rumah sakit di Indonesia tahun 2009 dan menempati urutan ke-3 dengan total 80.850 kasus, dan 1.013 diantaranya meninggal dunia dengan angka CFR 1,25\% (Kemenkes RI, 2010). Sedangkan pada tahun 2010 jumlah kasus demam tifoid dan paratifoid di Indonesia, masuk dalam 10 besar penyakit rawat inap di rumah sakit di Indonesia yang menempati urutan ke-3 mencapai 41.081 kasus dengan 274 kasus meninggal dunia dengan angka CFR sebesar 0,67\% (Kemenkes RI, 2011).

Keputusan Kementerian Kesehatan RI No. 364 tahun 2006 tentang pedoman pengendalian demam tifoid, menjelaskan bahwa beberapa keadaan kehidupan manusia yang sangat berperan pada penularan demam tifoid antara lain adalah higiene perorangan yang rendah, higiene makanan dan minuman yang rendah, kebersihan lingkungan yang kurang, tidak memadainya penyediaan air bersih, jamban yang ada tidak memenuhi syarat, tidak diobatinya pasien atau karier demam tifoid secara sempurna, serta program imunisasi untuk demam tifoid masih belum membudaya.

$\begin{array}{lr}\text { Menurut Peraturan } & \begin{array}{r}\text { Menteri } \\ \text { Nomor }\end{array} \\ \text { Kesehatan } & \text { tentang } \\ \text { 492/MENKES/PER/IV/2010 } & \text { kualitas air minum, untuk } \\ \text { persyaratan kne } & \text { air minum, }\end{array}$

diwajibkan untuk air minum yang aman bagi kesehatan harus memenuhi persyaratan fisika, mikrobiologis, kimia dan radioaktif. Hasil dari penelitian Putra (2012), menegaskan bahwa terdapat hubungan antara kebiasaan jajan dengan kejadian demam tifoid. Hal ini disebabkan sebagian besar jajanan tidak diberi penutup makanan.

\section{METODE PENELITIAN}

Metode penelitian ini adalah metode deskriptif-observasional dengan rancangan cross secsional study. pendekatan survei untuk mengetahui. Penelitian ini dilakukan di RSUD kota Kendari untuk lokasi pengambilan data serta pertemuan dan penyerahan kuisioner pada pasien demam tifoid yang didiagnosis yang merupakan sampel dari penelitian, rumah pasien yang menjadi responden penelitian untuk pengambilan sampel air yang akan di teliti dan Laboratorium Fakultas Kedokteran Universitas Halu Oleo untuk lokasi pemeriksaan bakteriologi untuk kualitas air minum dari rumah pasien yang akan diteliti. Pengambilan sampel dilakukan dengan menggunakan total sampling pada pasien demam yang di rawat inap di RSUD Kota Kendari pada bulan Januari-februari tahun 2018 periode 30 hari yang memenuhi kriteria inklusi dan eksklusi dengan cara pengambilan data menggunakan kuesioner selanjutnya pengambilan sampel air minum responden yang bersedia menjadi sampel penelitian kemudian sampel air minum tersebut di lakukan pemeriksaan mikrobiologi di Laboratorium mikrobiologi Fakultas Kedokteran Universitas Halu Oleo. 


\section{HASIL PENELITIAN}

Hasil penelitian ini di gambarkan secara berurutan yaitu analisis univariat untuk mengetahui ditribusi dari variabelvariabel yang diamati sehingga dapat mengetahui gambaran tiap variabel dan analisis bivariat untuk mengetahui hubungan atau korelasi antara variabel bebas dan variabel terikat. Berdasarkan hasil penelitian tentang hubungan kualitas air minum bersih dan kebiasaan makan/minum di luar rumah dengan terjadinya demam tifoid pada pasien rawat inap di RSUD Kota Kendari diperoleh hasil penelitian yang akan disajikan dalam bagian-bagian sebagai berikut :

\section{Analisis Univariat}

Distribusi karakteristik responden yang meliputi jenis kelamin, umur, pekerjaan, pemeriksaan laboratorium (yang meliputi hasil widal titer $\mathrm{O}$ dan titer $\mathrm{H}$ serta hasil pemeriksaan leukosit), kualitas air minum, sumber air bersih, dan kebiasaan makan/minum di luar rumah yang di bedakan antara pasien menderita dan tidak menderita. Distribusi karakteristik responden dapat di lihat pada Tabel 1, 2, 3, 4 dan 5.

\section{Analisis Univariat}

Distribusi karakteristik responden yang meliputi jenis kelamin, umur, pekerjaan, pemeriksaan laboratorium (yang meliputi hasil widal titer $\mathrm{O}$ dan titer $\mathrm{H}$ serta hasil pemeriksaan leukosit), kualitas air minum, sumber air bersih, dan kebiasaan makan/minum di luar rumah yang di bedakan antara pasien menderita dan tidak menderita. Distribusi karakteristik responden dapat di lihat pada Tabel 1.

Berdasarkan tabel 1, dapat ditemukan bahwa karakteristik keseluruhan responden berdasarkan jenis kelamin terbanyak yaitu responden perempuan dengan jumlah 20 orang $(52,6 \%)$ dan laki-laki sedang jumlah 18 orang $(47,4 \%)$. Berdasarkan karakteristik kelompok usia, keseluruhan responden yang terbanyak yaitu responden dengan rentang usia 14-21 tahun dengan jumlah 22 orang $(57,9 \%)$, usia 22-29 tahun dengan jumlah 8 orang $(21,1 \%)$, usia $30-37$ dan $38-45$ tahun 3 orang $(7,9 \%)$ dan terendah pada usia 46-53 dan 54-61 dengan jumlah 1 orang $(2,6 \%)$ dengan jumlah 1 orang $(2,6 \%)$. Karakteristik berdasarkan pekerjaan responden terbanyak yaitu mahasiswa/siswa dengan jumlah responden sebanyak 24 orang $(63,2 \%)$, wiraswasta sebanyak 12 orang $(31,6 \%)$, dan responden dengan pekerjaan sebagai PNS sebanyak 2 orang (5,3\%). Karakteristik berdasarkan hasil pemeriksaan laboratorium, menunjukan bahwa menurut pemeriksaan widal dengan titer $\mathrm{O} 1 / 80$ sebanyak 1 orang responden $(2,6 \%)$, titer O $1 / 160$ sebanyak 2 orang responden $(5,3 \%)$, dan titer $\mathrm{O} 1 / 320$ sebanyak 20 orang responden $(52,6 \%)$. Sedangkan pemeriksan widal dengan titer H $1 / 80$ sebanyak 3 orang responden (7,9\%), titer $\mathrm{H} 1 / 160$ sebanyak 9 orang responden $(23,7 \%)$, dan titer $\mathrm{H} 1 / 320$ sebanyak 11 orang responden $(28,9 \%)$.

Berdasarkan tabel 2, karakteristik kualitas air minum dari 38 responden, responden terbanyak dengan kualitas air minum yang tidak memenuhi syarat (di tumbuhi bakteri lain selain Salmonella thypi) dengan jumlah 22 sampel air $(57,9 \%)$ dan responden dengan kualitas air minum memenuhi syarat (tidak di tumbuhi bakteri lain maupun Salmonella thypi) dengan jumlah 16 sampel air $(42,1 \%)$. 
Tabel 1. Distribusi karakteristik responden berdasarkan jenis kelamin, usia, pekerjaan, pemeriksaan laboratorium

\begin{tabular}{|c|c|c|c|c|c|c|}
\hline \multirow[b]{2}{*}{ Karakteristik } & \multicolumn{2}{|c|}{ Menderita } & \multicolumn{2}{|c|}{ Tidak menderita } & \multirow{2}{*}{$\begin{array}{l}\text { Total } \\
(\mathbf{N})\end{array}$} & \multirow{2}{*}{$\begin{array}{c}\text { Persentase } \\
(\%)\end{array}$} \\
\hline & $\begin{array}{c}\text { Jumlah } \\
\text { (N) }\end{array}$ & $\begin{array}{c}\text { Persentase } \\
(\%)\end{array}$ & $\begin{array}{c}\text { Jumlah } \\
\text { (N) }\end{array}$ & $\begin{array}{c}\text { Persentase } \\
(\%)\end{array}$ & & \\
\hline \multicolumn{7}{|l|}{ Jenis Kelamin } \\
\hline Laki-laki & 7 & 18,4 & 11 & 28,9 & 18 & 47,4 \\
\hline Perempuan & 13 & 34,2 & 7 & 18,4 & 20 & 52,6 \\
\hline Total & 20 & 52,6 & 18 & 47,4 & 38 & 100 \\
\hline \multicolumn{7}{|l|}{ Usia } \\
\hline 14-21 tahun & 12 & 31,6 & 10 & 26,3 & 22 & 57,9 \\
\hline 22-29 tahun & 2 & 5,3 & 6 & 15,8 & 8 & 21,1 \\
\hline 30-37 tahun & 2 & 5,3 & 1 & 2,6 & 3 & 7,9 \\
\hline 38-45 tahun & 2 & 5,3 & 1 & 2,6 & 3 & 7,9 \\
\hline 46-53 tahun & 1 & 2,6 & 0 & 0 & 1 & 2,6 \\
\hline 54-61 tahun & 1 & 2,6 & 0 & 0 & 1 & 2,6 \\
\hline Total & 20 & 52,6 & 18 & 47,4 & 38 & 100 \\
\hline \multicolumn{7}{|l|}{ Pekerjaan } \\
\hline wiraswasta & 6 & 15,8 & 6 & 15,8 & 12 & 31,6 \\
\hline PNS & 2 & 5,3 & 0 & 0 & 2 & 5,3 \\
\hline Mahasiswa/siswa & 12 & 31,6 & 12 & 31,6 & 24 & 63,2 \\
\hline Total & 20 & 52,6 & 18 & 47,4 & 38 & 100 \\
\hline \multicolumn{7}{|l|}{ Pemeriksaan } \\
\hline \multicolumn{7}{|l|}{ laboratorium } \\
\hline \multicolumn{7}{|l|}{ Widal titer O } \\
\hline $1 / 80$ & 0 & 0 & 1 & 2,6 & 1 & 2,6 \\
\hline $1 / 160$ & 0 & 0 & 2 & 5,3 & 2 & 5,3 \\
\hline $1 / 320$ & 20 & 52,6 & 0 & 0 & 20 & 52,6 \\
\hline Tidak ada & 0 & 0 & 15 & 39,5 & 15 & 39,5 \\
\hline Total & 20 & 52,6 & 18 & 47,4 & 38 & 100 \\
\hline \multicolumn{7}{|l|}{ Widal titer $\mathrm{H}$} \\
\hline $1 / 80$ & 2 & 5,3 & 1 & 2,6 & 3 & 7,9 \\
\hline $1 / 160$ & 7 & 18,4 & 2 & 5,3 & 9 & 23,7 \\
\hline $1 / 320$ & 11 & 28,9 & 0 & 0 & 11 & 28,9 \\
\hline Tidak ada & 0 & 0 & 15 & 39,5 & 15 & 39,5 \\
\hline Total & 20 & 52,6 & 18 & 47,4 & 38 & 100 \\
\hline \multicolumn{7}{|l|}{ leukosit } \\
\hline Menurun & 8 & 21,1 & 4 & 10,5 & 12 & 31,6 \\
\hline Normal & 4 & 10,5 & 12 & 31,6 & 16 & 42,1 \\
\hline Meningkat & 8 & 21,1 & 2 & 5,3 & 10 & 26,3 \\
\hline Total & 20 & 52,6 & 18 & 47,4 & 38 & 100 \\
\hline
\end{tabular}

(Sumber: Data primer) 
Tabel 2. Distribusi karakteristik responden berdasarkan kualitas air minum

\begin{tabular}{lccccccc}
\hline \multirow{1}{*}{ Variabel } & \multicolumn{4}{c}{ Kejadian Tifoid } & \multicolumn{2}{c}{ Total } \\
& Menderita & \multicolumn{2}{c}{ Tidak menderita } & & \% \\
Kualitas air minum & $\mathbf{N}$ & $\mathbf{\%}$ & $\mathbf{N}$ & $\mathbf{\%}$ & $\mathbf{N}$ & $\mathbf{\%}$ \\
\hline Tidak memenuhi syarat & 13 & 34,2 & 9 & 23,7 & 22 & 57,9 \\
Memenuhi syarat & 7 & 18,4 & 9 & 23,7 & 16 & 42,1 \\
Total & 20 & 52,6 & 18 & 47,4 & 38 & 100 \\
\hline
\end{tabular}

Sumber: Data Primer

Tabel 3. Distribusi karakteristik responden berdasarkan kebiasaan makan/minum diluar rumah.

\begin{tabular}{|c|c|c|c|c|c|c|c|}
\hline \multirow[b]{3}{*}{$\begin{array}{l}\text { Kebiasaan } \\
\text { rumah }\end{array}$} & \multirow{3}{*}{$\begin{array}{l}\text { Variabel } \\
\text { makan/minum diluar }\end{array}$} & \multicolumn{4}{|c|}{ Kejadian Tifoid } & \multirow{2}{*}{\multicolumn{2}{|c|}{ Total }} \\
\hline & & \multicolumn{2}{|c|}{ Menderita } & \multicolumn{2}{|c|}{ Tidak menderita } & & \\
\hline & & $\mathbf{N}$ & $\%$ & $\mathbf{N}$ & $\%$ & $\mathbf{N}$ & $\%$ \\
\hline Baik & & 7 & 18,4 & 13 & 34,2 & 20 & 52,6 \\
\hline Kurang bai & & 13 & 34,2 & 5 & 13,2 & 18 & 47,4 \\
\hline Total & & 20 & 52,6 & 18 & 47,4 & 38 & 100 \\
\hline
\end{tabular}

Sumber: Data Primer

Tabel 4. Hubungan antara kejadian demam tifoid dengan kualitas air minum pada pasien rawat inap di RSUD Kota Kendari

\begin{tabular}{lcccccccc}
\hline \multicolumn{1}{c}{ Variabel } & \multicolumn{9}{c}{ Kejadian Tifoid } \\
& Menderita & \multicolumn{2}{c}{ Tidak } & Total & Penderita & & & P value \\
Kualitas air minum & $\mathrm{N}$ & $\%$ & $\mathrm{~N}$ & $\%$ & $\mathrm{~N}$ & $\%$ & \\
\hline Tidak memenuhi syarat & 13 & 34,2 & 9 & 23,7 & 22 & 57,9 & \\
Memenuhi syarat & 7 & 18,4 & 9 & 23,7 & 16 & 42,1 & 0,544 \\
Total & 20 & 52,6 & 18 & 47,4 & 38 & 100 & \\
\hline
\end{tabular}

Sumber : Data primer, 2018

Tabel 5. Hubungan antara kejadian demam tifoid dengan kebiasaan makan/minum diluar rumah pada pasien rawat inap di RSUD Kota Kendari

\section{Variabel}

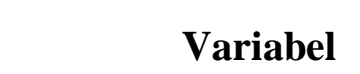

\section{Kejadian Tifoid}

Tidak
Menderita
menderita

Total

P value

\begin{tabular}{lrrrrrrr}
$\begin{array}{l}\text { Kebiasaan makan/minum } \\
\text { diluar rumah }\end{array}$ & $\mathbf{N}$ & $\mathbf{\%}$ & $\mathbf{N}$ & $\boldsymbol{\%}$ & $\mathbf{n}$ & $\mathbf{\%}$ & \\
\hline Baik & 7 & 18,4 & 13 & 34,2 & 20 & 52,6 & 0,049
\end{tabular}

Sumber : Data primer, 2018 
Berdasarkan table 3, Karakteristik berdasarkan kebiasaan makan/minum di luar rumah dari 38 responden penelitian, menunjukan bahwa responden terbanyak yaitu jumlah responden dengan kebiasaan makan/minum diluar rumah yang baik dengan jumlah 20 orang responden $(52,6 \%)$ dan kebiaaan makan/minumdiluar rumah yang kurang baik dengan jumlah 18 orang responden $(47,4 \%)$.

\section{Analisis Bivariat}

Hubungan kualitas air minum dengan terjadinya demam tifoid pada pada pasien rawat inap di RSUD Kota Kendari.

Berdasarkan tabel 4, dari 38 responden penelitian terdapat penderita demam tifoid dengan kualitas air yang memenuhi syarat sebanyak 7 orang responden $(18,4 \%)$ dan yang tidak memenuhi syarat sebanyak 13 orang responden $(34,2 \%)$. Sedangkan yang tidak menderita demam tifoid dengan kualitas air minum yang memenuhi syarat sebanyak 9 orang responden $(23,7 \%)$ dan yang tidak memenuhi syarat sebanyak 9 orang responden $(23,7 \%)$. Hasil analisis data pada tabel didapatkan bahwa nilai $P$ sebesar 0,544 atau nilai $p>0,05$ sehingga Ho di terima. Hal ini menunjukan bahwa tidak terdapat hubungan antara kejadian tifoid dengan kualitas air minum pada pasien rawat inap di RSUD Kota Kendari.

\section{Hubungan kebiasaan makan/minum diluar rumah dengan terjadinya demam tifoid pada pada pasien rawat inap di RSUD Kota Kendari.}

Berdasarkan Tabel 5, Dari 38 reponden penelitian terdapat penderita demam tifoid dengan kebiasaan makan/minum diluar rumah yang baik sebanyak 7 orang responden $(18,4 \%)$ dan yang memiliki kebiasaan kurang baik sebanyak 13 orang responden $(34,2 \%)$. Sedangkan yang tidak menderita demam tifoid dengan kebiaaan makan/minum di luar rumah yang baik sebanyak 13 orang responden $(34,2 \%)$ dan yang memiliki kebiasaan kurang baik sebanyak 5 orang responden $(13,2 \%)$. Hasil analisis data pada tabel dengan menggunakan uji chisquare, didapatkan bahwa nilai $P$ sebesar 0.049 atau nilai $p<0,05$ Ho di tolak. Hal ini menunjukan bahwa terdapat hubungan antara kejadian demam tifoid dengan kebiasaan makan/minum diluar rumah pada pasien rawat inap di RSUD Kota Kendari.

\section{PEMBAHASAN}

\section{Kualitas air minum terhadap kejadian demam tifoid}

Pada penelitian ini, hasil uji statistik dari 38 responden menunjukan bahwa kualitas air minum yang dimiliki memenuhi syarat dalam hal tidak terkandung/ditumbuhi bakteri salmonella thypi maupun bakteri lain pada pemeriksaan bakteriologi yaitu sebanyak 16 sampel air $(42,1 \%)$ sedangkan responden dengan kualitas air minum yang tidak memenuhi syarat dalam hal terkandung/ditumbuhi bakteri salmonella thypi atau bakteri lain pada pemeriksaan bakteriologi yaitu sebanyak 22 sampel air $(57,9 \%)$. Berdasarkan hasil analisis uji statistik, di peroleh nilai $p$ value $=0,544$ atau nilai $p>0,05$. Demikian dapat disimpulkan bahwa kualitas air minum tidak ada hubungannya dengan kejadian tifoid.

Berdasarkan tabel 4, hasil survey penelitian menggunakan medium NA yang dilanjutkan pada medium SSA dari 38 
sampel didapatkan 38 sampel air minum negatif terkandung bakteri salmonella thypi namun sekitar 22 sampel air minum $(57,9 \%)$ positif terkandung atau ditumbuhi bakteri lain selain salmonella thypi dengan karakteristik koloni yang di hasilkan berwarna pink, serta putih transparan. Hal ini menunjukan bahwa berdasarkan hasil uji statistik menunjukan tidak ada hubungan yang bermakna, tetapi walaupun sampel air minum tidak terkandung bakteri salmonela thypi yang dapat menyebabkan demam tifoid, namun secara langsung beberapa sampel air yang di konsumsi responden terkandung bakteri lain kemungkinan dapat menyebabkan terjadi atau tertularnya penyakit lain akibat tercemarnya air yang di konsumsi jika jumlah bakteri yang terkandung dalam air banyak. Hasil penelitian Sulistio (2012), menunjukan bahwa dari 15 sampel air minum isi ulang di Kelurahan Antang Kota Makassar yang diuji terdapat dua sampel yang positif bakteri Escherichia coli yaitu sampel yang diambil dari DAM Fikrah dan Mitra Utama, satu sampel positif Salmonella thypi yaitu sampel dari DAM Sukma. Air minum yang ideal seharusnya tidak mengandung bakteri patogen dan segala makhluk hidup yang membahayakan kesehatan manusia. Penyebaran bakteri Ecoli bisa melalui tiga jalan, yakni antara orang ke orang, kemudian dari makanan-minuman yang tidak dimasak dengan sempurna, dan bisa pula lewat vektor lalu menyebarkannya ke makanan dan dikonsumsi manusia, misalnya lalat. Sedangkan bakteri Salmonella thypi dapat tahan hidup lama dalam air, tanah atau bahan makanan. Dalam feces di luar tubuh manusia tahan hidup 1-2 bulan. Sehingga kondisi sanitasi di sekitar DAMIU serta hygiene pegawai / karyawan harus diperhatikan.

\section{Kebiasaan makan/minum diluar rumah terhadap kejadian demam tifoid}

Hasil penelitian terdapat 38 responden yang menunjukan bahwa 20 responden $(52,6 \%)$ dengan kebiasaan makan/minum diluar rumah yang baik dan 18 responden $(47,4 \%)$ dengan kebiasaan makan/minum diluar rumah yang tidak baik. Berdasarkan hasil analisis uji statistic, di peroleh nilai $p$ value $=$ 0,049 atau nilai $p<0,05$. Dengan demikian, dapat disimpulkan bahwa ada hubungan antara kebiasaan makan/minum diluar rumah dengan terjadinya demam tifoid pada pasien rawat inap di RSUD Kota Kendari. Hasil survey di lapangan menunjukan bahwa sebagian besar responden memiliki kebiasaan makan/minum diluar rumah sebanyak $>3$ kali seminggu walaupun beberapa responden juga mengatakan sering mengkonsumsi makan/minuman dirumah dalam sehari. Beberapa responden juga mengatakan makanan yang biasa di konsumsi tidak dibungkus, serta kurangnya fasilitas air cuci tangan di tempat makan dan kebiasaan cuci tangan responden yang kurang baik. Walaupun hasil pada hasil penelitian yang dilakukan pada sampel air minum yang di ambil di rumah responden tidak mengandung bakteri salmonella thypi, tetapi tidak menutup kemungkinan responden tertular bakteri tersebut melalui air yang di konsumsi di luar rumah. Hal ini dapat di sebabkan sebagian besar dari responden merupakan mahasiswa dan pelajar, dimana kebiasaan makan/minum di luar rumah juga merupakan suatu hal yang sering dilakukan karena aktifitas sebagian besar 
di lakukan di luar rumah dari pada di rumah yang menyebabkan sebagian besar responden makan di luar rumah atau sekitar kampus saja misalnya kantin ataupun warung makan terdekat yang belum dapat terjamin kebersihannya baik dari makanan/minuman yang dikonsumsi itu sendiri ataupun kebersihan alat-alat yang di gunakan pada saat makan.

Hasil penelitian ini sejalan dengan penelitian yang di lakukan Artanti (2013) yang menunjukan bahwa ada hubungan antara kebiasaan makan di luar rumah dengan kejadian Demam Tifoid di Wilayah Kerja Puskesmas Kedungmundu Kota Semarang dengan nilai $p(0,005)<\alpha$ $(0,05)$. Hal ini menunjukkan sebagian besar responden memiliki kebiasaan makan diluar rumah. Padahal kebanyakan makanan siap saji atau makanan warung biasanya banyak mengandung penyedap rasa dan kehigienisan yang belum terjamin, dibandingkan dengan memasak makanan sendiri di rumah yang lebih memperhatikan kebersihan dalam mengolah makanan. Oleh karena itu, untuk setiap individu harus memperhatikan kualitas makanan dan minuman yang mereka konsumsi serta memperhatikan kebersihan diri sebelum makan untuk memperkecil kemungkinan tercemarnya bakteri salah satunya Salmonella thyphi untuk mengurangi terjadinya demam tifoid.

\section{SIMPULAN}

Berdasarkan hasil penelitian dan pembahasan didapatkan simpulan bahwa Tidak ada hubungan antara kualitas air minum dengan terjadinya demam tifoid pada pasien rawat inap di RSUD Kota Kendari.Ada hubungan antara sumber air bersih dengan terjadinya demam tifoid pada pasien rawat inap di RSUD Kota Kendari. Ada hubungan antara kebiasaan makan/minum di luar rumah dengan terjadinya demam tifoid pada pasien rawat inap di RSUD Kota Kendari.

\section{SARAN}

Perlu dilakukan peningkatan program promosi kesehatan di Rumah Sakit meliputi penyuluhan perilaku hidup bersih dan sehat untuk mencegah meningkatnya kejadian demam tifoid. Pihak PDAM diharapkan untuk memperhatikan dan meningkatkan kualitas air bersih dalam hal memenuhi syarat (fisik, mikrobiologi, kimia dan radioaktif) untuk menghindari kontaminasi dari bakteri yang dapat menyebabkan penyakit. Masyarakat perlu menjaga kebersihan baik kebersihan diri maupun lingkungan serta memperhatikan kebersihan dari makanan/minuman yang di konsumsi untuk menghindari terjadinya Demam Tifoid. Bagi peneliti selanjutnya, diharapkan untuk pemeriksaan kualitas air minum di lanjutkan dengan pemeriksaan gram dan uji biokimia untuk mengidentifikasi bakteri signifikan yang terkandung dalam air.

\section{DAFTAR PUSTAKA}

Amiruddin, R.R., Darniati, Ismail. 2017. Isolasi dan Identifikasi Salmonella sp pada Ayam Bakar di Rumah Makan Kecamatan Syiah Kuala Kota Banda Aceh. JIMVET. 01(3): 265-27.

Artanti, NW. 2013. Hubungan Antara Sanitasi Lingkungan, Higiene Perorangan, Dan Karakteristik Individu Dengan Kejadian Demam Tifoid Di Wilayah Kerja Puskesmas Kedungmundu Kota Semarang Tahun 2012. Skripsi. 
Program Studi Ilmu Kesehatan Masyarakat Universitas Negeri Semarang. Semarang.

Azhar, K., Dharmayanti, I., Anwar, A. 2014. Pengaruh Akses Air Minum Terhadap Kejadian Penyakit Tular Air (Diare Dan Demam Tifoid). Buletin Penelitian Sistem Kesehatan, 17(2) : 107-114

Dinas Kesehatan Provinsi Sulawesi Tenggara. 2018. Profil Kesehatan Sulawesi Tenggara Tahun 2017. Data Dan Informasi Dinas Kesehatan Provinsi Sulawesi Tenggara. Kendari.

Handini, S. 2009. Tingkat Pengetahuan Siswa Madrasah Tsanawiah (Mts) Al-Sa'adah Pondok Jaya Terhadap Demam Tifoid Tahun 2009. Skripsi. Program Studi Ilmu Keperawatan Universitas Islam Negeri Syarif Hidayatullah. Jakarta.

Inawati. 2009. Jurnal Demam Tifoid. Surabaya: Jurnal Edisi Khusus Desember.

Irsan. 2014. Analisis Faktor-Faktor Risiko Demam Tifoid Di Puskesmas Poasia. Skripsi. Program Studi Pendidikan Dokter Universitas Halu Oleo. Kendari.

Kementrian Kesehatan Republik Indonesia. 2010. Profil Kesehatan Indonesia Tahun 2009. Kementerian Kesehatan Republik Indonesia. Jakarta.

Kementrian Kesehatan Republik Indonesia. 2011. Profil Kesehatan Indonesia Tahun 2010. Kementerian Kesehatan Republik Indonesia. Jakarta.

Kementrian Kesehatan Republik Indonesia. 2006. Keputusan
Menteri Kesehatan Republik Indonesia Nomor 364/Menkes/SL/V/2006 Tentang Pedoman Pengendalian Demam Tifoid. Departemen Kesehatan Republik Indonesia. Jakarta.

Peraturan Menteri Kesehatan Republik Indonesia Nomor 492 tahun 2010. Persyaratan Kualitas Air Minum. Jakarta.

Pramitasari, O.P. 2013. Faktor Risiko Kejadian Penyakit Demam Tifoid Pada Penderita Yang Dirawat Di Rumah Sakit Umum Daerah Ungaran. Tesis.

Dipenogoro:Diponegoro University.

Putra, A. 2012. Hubungan antara Tingkat Pengetahuan Ibu tentang Demam Tifoid terhadap Kebiasaan Jajan Anak Sekolah Dasar. FK UNDIP. Semarang.

Ristanti, Tesa. 2017. Kualitas Bakteriologis Depot Air Minum Isi Ulang (DAMIU) Masyarakat Di Daerah Pesisir Kota Kendari. Skripsi. Program Studi Pendidikan Dokter Universitas Halu Oleo. Kendari

Sulistio, Dwi. 2012. Uji Keberadaan Bakteri Escherichia Coli dan Salmonella Thypi Pada Air Minum Isi Ulang Di Kelurahan Antang Kota Makassar. Skripsi. Program Studi Kesehatan Masyarakat Universitas Islam Negeri Alauddin Makassar. Makassar. 